\title{
Distinguishing Perceived Hope and Dispositional Optimism: Theoretical Foundations and Empirical Findings beyond Future Expectancies and Cognition
}

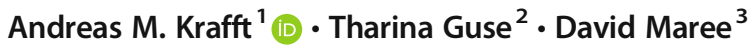 \\ Accepted: 26 November 2020/ Published online: 6 February 2021 \\ (C) The Author(s) 2021
}

\begin{abstract}
At first glance, hope and optimism appear to be two almost identical concepts. The predominant cognitive theories maintain that both are based on positive future expectancies regarding goal attainment. However, other approaches recommend distinguishing between hope and future expectancies and sustain that the differences between hope and optimism are of a more substantial nature. The present study investigates the distinction between a new short instrument to measure hope as perceived by the general public, and dispositional optimism as measured by the revised Life Orientation Test (LOT-R) in a South African sample. After comparing both instruments using confirmatory factor analysis and exploratory structural equation modelling in Mplus, a number of encouraging results emanated from the data. First, the Perceived Hope Scale (PHS) is a unitary and coherent measure of perceived hope. Second, perceived hope, as measured by the PHS, and optimism and pessimism as measured by the LOT-R, are psychometrically distinguished latent dimensions, optimally specified by their indicator variables. Furthermore, perceived hope represents a fundamental construct in the prediction of health outcomes and well-being and is an important antecedent to optimism and dispositional hope. Perceived hope is thus an important additional facet to consider in investigating wellbeing.
\end{abstract}

Keywords Perceived hope $\cdot$ Dispositional hope $\cdot$ Optimism $\cdot$ Pessimism $\cdot$ Future expectancies

\section{Background and Purpose}

For several years, a recurrent debate has taken place regarding the conceptual and empirical overlap and/or differences between hope and optimism (Alarcon et al. 2013;

Andreas M. Krafft

andreas.krafft@unisg.ch

Extended author information available on the last page of the article 
Bruininks and Malle 2005; Snyder et al. 2001). The difficulty in distinguishing the two resides on the one hand in the often undifferentiated meaning and use of these folk terms in everyday life, and on the other hand, in the many and often opposing conceptual definitions of each construct developed over decades and even centuries by philosophers and social scientists. The importance of a positive attitude towards the future and its effects in terms of better health, quality of life, individual performance and social relations has been widely documented (Andersson 1996; Cheavens et al. 2005). Nevertheless, the discussion continues about the fundamental nature of hope and optimism for example as cognition or emotion, self-efficacy or trust, virtue or mere disposition, and the role of other factors such as basic beliefs, values and religious faith (Eliott 2005; Lopez et al. 2003). In recent years, several authors have expressed their concerns regarding the mainstream cognitive approach in research on hope. In particular, they pleaded for a more sensitive investigation of this phenomenon, taking the personal experiences perceived by people more seriously into account, as has been done in other scientific fields, such as nursing research (Aspinwall and Leaf 2002; Bruininks and Malle 2005; Scioli and Biller 2009; Tennen et al. 2002; Tong et al. 2010). Following these recommendations, the international Hope-Barometer research project was established to investigate hope and its many dimensions, elements and forms, in relation to other positive experiences and attitudes as faced and perceived by ordinary people (Krafft and Walker 2018a, b).

In the theoretical section of this article, a summary of the recently most frequently used definitions of hope and optimism as well as the diverse arguments proposed by several authors to conceptually distinguish hope from optimism are presented, followed by the explanation of the necessity to study hope as perceived by ordinary people in their everyday life. Using results from original data collected via the Hope-Barometer crosssectional survey in South Africa, the first purpose of this contribution is to validate the English version of the newly developed Perceived Hope Scale (PHS) (Krafft et al. 2019) by evaluating its factor structure, and distinguishing perceived hope from dispositional optimism as measured by the revised version of the Life Orientation Test (Scheier et al. 1994). Furthermore, our aim is to examine the utility of the Perceived Hope Scale to predict measures of mental health and well-being beyond the variance explained by the LOT-R and the Dispositional Hope Scale (DHS) (Snyder et al. 1991).

\section{Conceptualizing Hope and Optimism}

\subsection{Hope and Optimism as Goal-Oriented and Expectancy Driven Cognition}

The two most widely diffused psychological theories of hope and optimism are those of dispositional hope developed by Snyder (1994) and dispositional optimism by Scheier and Carver (1985). Both theories have many similarities and common roots: They are conceptualized as (a) stable personality traits, (b) cognitive constructs, (c) based on general expectancies, (d) related to worthy personal goals, (e) oriented to the future, and (f) operating as important determinants of behavior.

The broader expectancy-value based theory of self-regulation formulated by Carver and Scheier (1981) postulates that human behavior is essentially directed to the pursuit of goals, entailing three fundamental elements: the importance of the goal, the expectancy of goal-attainment and the psychological engagement and motivation towards goal- 
achievement. The higher the perceived importance and value of a certain goal and the higher the subjective expectancy that this goal can be attained, the higher also the motivation to remain engaged in goal-orientated behavior, especially in situations where possible obstacles and adversities must be overcome. People with an optimistic attitude expect positive outcomes to occur because they are confident that their goals can be achieved regardless of external impediments. In contrast, people with a pessimistic mindset will give up their efforts more quickly since they do not have sufficient confidence regarding the attainability of their goals and therefore expect unfavorable outcomes to happen (Carver and Scheier 2014). However, the focus of this theory of optimism is on outcome expectancies rather on expectancies of self-efficacy. This means that optimism is related to a generalized expectancy that good rather than bad things will happen, independently from the sources and reasons. One can be optimistic because he or she believes in his/her own capabilities, in the support and assistance of other people, in luck or providence, etc. (Carver and Scheier 2003). Positive and negative expectations about the future strongly influence the general experiences, affect and behavior of people.

Dispositional optimism, as defined by Scheier and Carver (1985) and dispositional hope, as defined by Snyder (1994) are both conceptualized as stable personality traits based on goaloriented cognitive processes related to general (instead of specific) expectancies about one's own future. The main difference is that Snyder's theory of hope has a self-centered character in that it refers to the person's control and efficacy to attain personal goals. Thus, hope concerns self-initiated action to reach desirable outcomes (Alarcon et al. 2013). The two elements of dispositional hope are agency, defined as the belief in one's energy and motivation to achieve a goal, and pathways, seen as the confidence in one's ability to develop plans to meet goals especially when confronting obstacles (Snyder et al. 1991; Snyder 2002). In sum, dispositional optimism and dispositional hope are distinguished by the grounds on which the expectancies about future goal-related outcomes are based upon: a general perception of confidence in case of optimism and a general belief of self-control and self-efficacy in case of hope. A recent meta-analysis on the nature of hope and optimism supported this distinction (Alarcon et al. 2013). However, less is known about the distinction between optimism and alternative ways to measure hope, such as perceived hope (Krafft et al. 2019; Krafft and Walker 2018a, b).

\subsection{Alternative Views on Hope and Optimism}

In order to extend the understanding of hope, and to elaborate alternative conceptualizations, several authors have investigated the meaning and conceptions of hope. This investigation included the many elements and dimensions hope entails, as experienced and perceived by ordinary people, individuals with serious illnesses and their relatives (e.g. Averill et al. 1990; Benzein et al. 2001; Bruininks and Malle 2005; Eliott and Olver 2002; van der Geest et al. 2015; Herth 2005). The overall conclusion is that hope is much more complex and that the differences between hope and optimism are more substantial, and lie deeper than suggested by the cognitive perspective (Aspinwall and Leaf 2002; Bruininks and Malle 2005; Eliott 2005; Pruyser 1986; Scioli et al. 1997). The main findings of many decades of empirical research and theory building highlight the fundamental nature of hope as an existential human virtue and character strength (Miller 2012; Peterson and Seligman 2004), the central role of trust and social relationships (Tennen et al. 2002) as well as the basic difference between hope and expectancies (Montgomery et al. 2003; Leung et al. 2009). It also points to the emotional, spiritual and religious 
dimensions (Fredrickson 2002, 2013; Farran et al. 1995; Pruyser 1986; Scioli and Biller 2009; Vaillant 2008) and the culture specific character of hope (Averill et al. 1990; Averill and Sundararajan 2005).

The most fundamental deviation of this broader conceptualization of hope from the cognitive theories rests on the findings of several studies revealing that hope is basically distinct from expectancies (Clayton et al. 2008; David et al. 2004; Montgomery et al. 2003). These studies could empirically distinguish between the subjective likelihood of occurrence ascribed to a particular future event and people's own beliefs that a desired outcome is possible. While expectancies are based on evidence, reason and an estimated probability of occurrence, hope is related to the desirability of the event, which is potentially possible but not necessarily probable (Kamihara et al. 2015; Leung et al. 2009). This does not mean that expectancies are more real than hopes, but that hope is of a different nature, mainly grounded on personal ideals, values and beliefs instead of on "objective" facts. The distinction between expectancies and hope becomes more apparent in dire and existential situations where people fear a bad outcome yet yearn for the best, maintaining hope and at the same time preparing for the worst (Renz et al. 2009; Shirado et al. 2013).

Bruininks and Malle (2005) came to similar conclusions when asking people to distinguish between hope and optimism. The participants of their study characterized optimism as a cognition related to general outcomes with a high degree of personal control and a greater likelihood of fulfillment. In contrast, people used the term hope for aspects in their life which were more significant and emotionally important to them, but with less personal control and lower likelihood of occurrence. Furthermore, objects associated with hope more often included pro-social and altruistic motives, for example hoping for another person's affairs (Bruininks and Malle 2005).

These and other findings seem to indicate that hope is essentially an existential human need, directed at matters of vital interest. It has a strong emotional character, depending less on cognitive and rational facts, but rather reflecting a basic sense of trust associated with good social relationships, values and personal beliefs, and in turn having a positive self-transforming effect on the hoping person (Averill and Sundararajan 2005; Fredrickson 2013; Scioli and Biller 2009; Tennen et al. 2002). As a human virtue, hope is thought to entail a positive view of the self and the goodness of the world, especially during adverse situations (Peterson and Seligman 2004). It is rooted in trust experiences and the attachment to other people (family and friends), related to spiritual and religious faith, which goes beyond rational knowledge, and the intimate connection to a benevolent higher power (Dufault and Martocchio 1985; Erikson 1963; Farran et al. 1995; Scioli and Biller 2009; Scioli et al. 2011). Following these diverse views on hope, Krafft et al. (2019; Krafft and Walker 2018a) proposed an alternative approach to assess hope, referred to as perceived hope. Measured by the Perceived Hope Scale (PHS), perceived hope reflects hope as experienced by people, instead of the motivation and expectancy of goal attainment.

In the next section, we describe the PHS as well as other measures relevant to our study, in order to distinguish between hope and optimism.

\subsection{Measures of Optimism, Perceived Hope and Related Variables}

\subsubsection{The Revised Life Orientation Test}

Scheier and Carver (1985) developed the Life Orientation Test (LOT) and its revised version (LOT-R) (Scheier et al. 1994) to assess the level of dispositional optimism as an enduring personality trait. The LOT-R measures expectations about one's future. It 
assesses the degree of how far one expects good rather than bad thingswill happen in one's life, independently from the sources or the causes leading to them. The scale is composed of three positively worded items (e.g. "Overall, I expect more good things to happen to me than bad") and three negatively formulated items (e.g. "I hardly ever expect things to go my way") (Scheier et al. 1994). According to the bipolar understanding of optimism as a continuum between the two opposites ranging from high optimism to high pessimism, the authors have conceived the scale to provide a unique score. Meanwhile, many empirical studies in different countries have demonstrated that the LOT-R (similar to the original LOT) represents two separate factors tapping the two partially independent dimensions of optimism and pessimism (Glaesmer et al. 2012; Herzberg et al. 2006; Kubzansky et al. 2004; Ribeiro et al. 2012; Segerstrom et al. 2011). Beyond possible method bias, the two subscales show only moderate to low correlation coefficients with each other and are distinctively related to mental health and well-being variables. Whereas optimism seems to better predict positive constructs such as positive affect and life-satisfaction, pessimism is more strongly associated with negative affect and depression (Chang et al. 1997; Marshall et al. 1992; Robinson-Whelen et al. 1997; Scheier et al. 2001). Following these findings, Carver and Scheier (2014) recommended using the overall scale score as well as the optimism and pessimism sub-scale scores separately.

\subsubsection{The Perceived Hope Scale}

Over the past decades, several multidimensional scales have been developed in order to grasp the many elements the phenomenon of hope might contain, (e.g. Farran et al. 1995; Herth 1991; Scioli et al. 2011). However, concerns have been raised regarding the confounding risk and the cultural bias of these measures (Tennen et al. 2002, Tong et al. 2010). The Perceived Hope Scale was developed, following the plea of several authors for a concise, simple and psychometrically sound instrument for studying hope as perceived by ordinary people (Averill et al. 1990; Tennen et al. 2002; Tong et al. 2010; Krafft et al. 2019). The PHS was adapted and further elaborated from the WHOQOL-SRPB questionnaire (WHOQOL SRPB Group 2002) as a one-dimensional measure of hope. The resulting six items assess the general level of hope, the broad belief in the fulfillment of one's hopes, in how far hope outweighs anxiety, whether hope improves the quality of one's life and the question, if one can remain hopeful in difficult times. Therefore, the PHS does not measure future expectancies of goal attainment, but the experience of hope as directly perceived by people, without enquiring about the sources and mechanisms of hope. The scale contains general (e.g. 'My hopes are usually fulfilled') as well as situational items (e.g. 'I feel hopeful') and all items are positively worded. In a validation study using the German version of the scale, the authors demonstrated the one-factor structure and the reliability of the scale, the convergent validity with regard to other measures like gratitude, selfefficacy, resilience, generativity and spiritual beliefs as well as its discriminant and predictive value vis-á-vis the Dispositional Hope Scale (Krafft et al. 2019). The authors concluded that the PHS measures a distinct basic experience in contrast with two dimensions of agency and pathways as found in the DHS of Snyder (2002).

The PHS and the LOT-R share the assessment of a general perception of hope and optimism, without enquiring about the roots or agents of the phenomenon. In both cases, the sources of hope / optimism can be many, for example the belief in one's luck, the faith in a benevolent higher power or the confidence in other people. Some items of both scales 
contain similar basic meanings, for example: "Even in difficult times I am able to remain hopeful" (PHS) and "In uncertain times, I usually expect the best" (LOT-R); "I am hopeful with regard to my life" (PHS) and "I'm always optimistic about my future" (LOT-R); as well as "In my life hope outweighs anxiety" (PHS) and "Overall, I expect more good things to happen to me than bad" (LOT-R). With these fundamental similarities in mind, it is necessary to assess whether the PHS and the LOT-R are measuring the same basic experience or if people are able to intuitively distinguish between hope and optimism.

\subsubsection{Hope, Optimism, Health and Well-Being}

The fact that dispositional hope and dispositional optimism are associated with different indicators of health and well-being has been well documented in many studies (for an overview see Alarcon et al. 2013; Bailey et al. 2007; Carver et al. 2010; Rasmussen et al. 2009). However, several authors (Benyamini and Roziner 2008; Magaletta, and Oliver 1999; Smith et al. 1989) questioned the extent to which optimism, pessimism and hope (represented by the agency and pathways constructs) independently contribute to predict health and well-being outcomes and how far they are distinguishable from each other.

The same question must be asked when introducing a new instrument such as the Perceived Hope Scale (PHS). For this reason, the present study concludes with an evaluation of the predictive capacity and utility of the PHS compared to the LOT-R and the Dispositional Hope Scale. The research question is whether the PHS adds to the prediction of well-being indicated by depression/anxiety (Kroenke et al. 2009), satisfaction with life (Diener et al. 1985), harmony in life (Kjell et al. 2016) and subjective happiness (Lyubomirsky and Lepper 1999) beyond the variance explained by the LOT-R and the Dispositional Hope Scale (DHS).

\section{The Current Study}

\subsection{Purpose and Steps}

Based on the theoretical considerations about conceptual similarities and differences between hope and optimism, the purpose of the present study was to explore and evaluate the discriminant criteria between the Perceived Hope Scale and the revised version of the Life Orientation Test and its sub-constructs, optimism and pessimism. Furthermore, we wanted to assess the usefulness of the PHS in predicting health and well-being outcomes. To accomplish these purposes, the study is divided into three steps:

Step 1: Evaluation of the factor structure and reliability of the English version of the PHS. As conceptually defined, we expect that the six items of the PHS will clearly and strongly load on only one factor with a high reliability.

Step 2: Assessment of the discriminant value of the PHS compared to the LOT-R. We expect hope, optimism, and pessimism to be distinct, but moderately to strongly correlated independent latent factors, thus showing clear psychometric distinction. 
Step 3: Appraisal of the predictive power and utility of the PHS vis-á-vis the LOT-R and the DHS in relation to anxiety/depression, life-satisfaction, harmony in life, and subjective well-being. We anticipate that the PHS strengths the prediction of these variables to measure health and well-being in addition to dispositional optimism and dispositional hope.

\subsection{Participant Samples and Procedures}

The study employed two South African samples. Data for the main sample used in all steps, except in the initial measurement model analysis, were gathered through the crosssectional Hope-Barometer survey. The present study is based on original data collected online via social media, electronic newspapers and email during November 2017. In total, 427 people completed the questionnaire. This sample of 427 cases was screened to identify multivariate outliers using Mahalanobis distances, taking into account the variances and covariances of the 6 items of the PHS and the 6 items of the LOT-R. Using the chi-square function $(d f=12)$ and defining the threshold significance level at $p<.001$ as recommended by Raykov and Marcoulides (2012), 18 multivariate outliers were identified and removed from the dataset. In the 409 remaining cases, both the items of the PHS and of the LOT-R were slightly skewed but all within the recommended threshold values of skewness $<|2|$ and kurtosis $<|3|$ (West et al. 1995), rendering the database appropriate for factor analysis.

In terms of the demographic structure of the sample, most (286) were female and 123 were male. The mean age was $38.78(S D=14.43)$, varying from 18 to 79 . Regarding race, the majority of the sample constituted White participants (237) followed by 139 Black, 19 Indian, 8 Coloured (mixed race) and 6 others. In terms of family status most participants (169) were married, 80 still living with their parents, 72 single, 59 in a partnership, 21 separated or divorced and 8 widowed. The sample reflected high levels of education with 282 participants holding a university degree, 45 with a diploma, 74 with high school up to grade 12, 7 with high school up to grade 10 and one who did not finish school. The majority (237) was employed full-time, 100 were enrolled in education or training, 29 held a part-time job, 22 were retired, 11 unemployed and 10 working in the household and/or raising children. In terms of religious denomination, the sample consisted of $314 \mathrm{Chris-}$ tians, 80 denominated themselves as being spiritual persons outside the traditional world religions, 30 without religion, 10 Muslims, 9 Jewish, 7 Hindus, two Buddhists, and 19 with a different faith. To summarize, our sample reflected diversity in terms of ethnicity, age and gender, which could strengthen the findings.

For the initial exploration of the PHS factor structure in step 1 we employed a different sample of 251 students enrolled at the University of Johannesburg, collected in 2016. Adopting the same statistical procedure as for the main sample, but including only the six items of the PHS in the data screening, seven multivariate outliers were identified and removed from the dataset. The remaining 244 cases included in the measurement model analysis were characterized by the following demographic characteristics: 167 female and 76 male participants ( 1 missing answer) ranging between 18 and $25(M=20.57 ; S D=$ 1.95). Most (187) were Black followed by 30 White, 18 Indian, six mixed race, and two others (one missing answer). The items were also slightly skewed to the right side of the scale but all within the threshold values for skewness $<|2|$ and kurtosis $<|3|$. 
Ethical approval for the original studies from which the samples were obtained were provided by the Faculty of Humanities Research Ethics Committee in 2016 (student sample) and 2017 (main sample - Hope Barometer Survey).

\subsection{Measures}

\subsubsection{Instruments to Measure Hope and Optimism}

The Perceived Hope Scale (PHS) The PHS measures the level of hope as perceived by the people (Krafft et al. 2019). It was conceived as a unidimensional measure including 6 positively worded items to be rated on a 6-point Likert scale ranging from 0 (strongly disagree) to 5 (strongly agree). In the validation study of the German sample the six items achieved a high internal consistency with Cronbach alpha values between $\alpha=.87$ and $\alpha=$ 89. In the present study the following Cronbach Alpha reliability indices were obtained: .886 in the 409 sample, and .930 in the 244 sample (Omega reliability index of $.917(N=$ 409) and .948 $(N=244))$.

The Life Orientation Test Revised (LOT-R) The LOT-R measures dispositional optimism as general expectancy towards the future (Scheier et al. 1994). From the six items to be rated on a 6-point Likert scale from 1 (strongly disagree) to 6 (strongly agree), three are positively and three are negatively worded. To obtain an overall score for the LOT-R, the negatively worded items have to be reverse coded. Several authors recommend calculating a score for optimism with the three positively worded items and another score for pessimism with the three negatively worded items (e.g. Chang and Sanna 2001). In Scheier et al.'s (1994) revision paper the internal consistency of the six items was $\alpha=.78$. For a web sample Segerstrom et al. (2011) reported Cronbach alpha values of $\alpha=.83$ for the entire scale, $\alpha=.71$ for the three optimism and $\alpha=.79$ for the three pessimism items. In the present study the following Cronbach alpha reliability indices were obtained: .819 for Optimism $($ Omega $=.895), .773$ for pessimism $($ Omega $=.870)$ and .719 for the entire LOT-R $($ Omega $=.815)$.

The Dispositional Hope Scale (DHS) The DHS contains four items to assess the motivational dimension of agency and four items to assess the cognitive dimension of pathways. In past studies, Cronbach alpha coefficients for the overall ADHS ranged from .74 to .84, from .71 to .76 for the four items of the Agency subscale, and from .63 to .80 for the four items of the pathways subscale (Snyder et al. 1991). In our sample, Cronbach alpha reliability indices resulted to be .889 for the DHS (Omega=.912), .804 for agency $($ Omega $=.871)$, and .853 for pathways $($ Omega $=.901)$.

\subsubsection{Additional Measures to Evaluate the Predictive Utility of the PHS}

Depression and Anxiety The ultra-brief Patient Health Questionnaire for Depression and Anxiety (PHQ-4) is a composite four-item scale for measuring both phenomena (Kroenke et al. 2009). Since the questionnaire asks the participants to assess how often they are bothered by certain negative feelings, responses are scored from 0 (not at all), 1 (several days), 2 (more than half the days) to 3 (nearly every day). The alpha-coefficient reported in 
the validation study was .85 . In the present study the following Omega reliability index for the measure of depression and anxiety was obtained: $855(n=409)$ (Cronbach alpha $=.851)$.

The Satisfaction with Life Scale (SLS) The SLS was designed to assess global life satisfaction, defined as the comparison of life circumstances to one's expectations (Diener et al. 1985). The SLS consists of five items scored on a 7-point scale from 1 (strongly disagree) to 7 (strongly agree). The authors reported a coefficient alpha of .87. In the present study the following Omega reliability index for the SWLS was obtained: .877 $(n=409)($ Cronbach alpha $=.868)$.

The Harmony in Life Scale (HLS) Recently, Kjell et al. (2016) developed the HLS to measure psychological experiences of inner balance, peace of mind, calm and unity. The authors highlight the concept of harmony in life as being related to a holistic world-view that entails a more balanced approach to personal well-being. The five items $(\alpha=.89)$ are scored on a 7-point scale from 1 (strongly disagree) to 7 (strongly agree). In the present study the following Omega reliability index for the HLS was obtained: $902(n=409)$ $($ Cronbach alpha $=.899)$.

The Subjective Happiness Scale (SHS) The SHS assesses the extent to which people feel happy or unhappy, using four items (Lyubomirsky and Lepper 1999). The possible scores range from 1 to 7 per item. The reported Cronbach alphas in the authors' studies ranged from .79 to .94 . In our study the Omega index is .896 and Cronbach alpha coefficient .816 .

\subsection{Statistical Analyses}

To accomplish the empirical objectives as outlined in steps 1 to 3, we employed structural equation modeling in Mplus (Byrne 2012; Muthén and Muthén 1998-2017). In all measurement and structural model analyses, the MLR estimator, which is more robust to non-normality, was used. We relied on model fit indices for demonstration of model adequacy in both measurement and structural models; on correlation estimates for intervariable associations; and on direct effect estimates for influence of latent variables on others (Byrne 2012; Geiser 2013; Hu and Bentler 1999).

Step 1 was concerned with evaluating the intended unidimensional structure of the six items of the PHS. In this first step, we estimated the unidimensional measurement model of the PHS using CFA in sample $1(n=251)$, and replicated the procedure in sample 2 $(n=409)$.

The purpose of step 2 was to assess, by means of CFA, ESEM and a bifactor ESEM, whether hope, as measured by the PHS, can be psychometrically distinguished from dispositional optimism as measured by the LOT-R and its sub-constructs optimism and pessimism. Step 2 applied a series of measurement models consisting of items or indicators of PHS and LOT-R. Our strategy followed the example of similar studies investigating psychological constructs suspected of harboring a general underlying or overarching factor (McLarnon and Tarraf 2017; Stenling et al. 2015). Because of the equivocal nature of language, the formulation and understanding of items may have 
unintended true score variance overlap with other constructs (Morin et al. 2016). In the case of several hope-related instruments the similar nature of items would be expected to cause overlap with each other. The sources of construct relevant variance we have in mind are the overlap of items with (a) the instrument's own subconstructs if any, (b) with a global construct underlying an instrument's subconstructs (Morin et al. 2016b) and (c), with a construct measured by other instruments (Morin et al. 2016a). An investigation of discriminant validity of the PHS and LOT-R would encounter all three sources of true score variance. The expectation is that the PHS should be unidimensional, although item variance might overlap with the LOT-R and/or a global hope-like construct.

Thus, to examine the unidimensional nature of the PHS and its discriminant validity as compared to the LOT-R a series of models were fitted as mentioned above. First, a baseline one-factor CFA was done (Model 1) that includes all the items of the PHS and LOT-R to determine the unidimensional nature of all the items (i.e. how well do they measure a similar construct?). Secondly, the intended subfactors of the PHS and LOT were examined as first order CFA factors (PHS, Optimism and Pessimism) (Model 2a) and as a second order CFA factor for LOT-R (PHS, LOT as second order factor of optimism and pessimism) (Model 2b).

In an investigation of discriminant validity, the sources of true score variance can be easily missed because classical CFA places restrictions on item and factor cross loadings. The requirement of zero cross-correlations, as Morin et al. (2016a) have pointed out, inflate item loadings and/or factor loadings depending on the model used. Thus, true score variance can be misattributed. ESEM outperforms CFA in that it allows for the modelling of (theoretically plausible) cross-loadings, and it has less reliance on model modification indexes (Asparouhov and Muthén 2009). To examine adjacent factors with the possibility of PHS cross-loading on LOT-R factors, an ESEM model was fitted (three factors with PHS, optimism and pessimism) (Model 3). Given the redundancy of the LOT second order factor (Model 2b) (see below), it was not included in further analyses.

To determine the extent to which PHS and LOT overlap with a global hope factor, a Bifactor ESEM model was fitted (Model 4). Bifactor analysis is useful to identify uniand multidimensionality of an instrument having relatively similar constructs but also an underlying general dimension (Wang and Wang 2019). The ESEM part of this model allowed the zero cross-correlation requirement between items and factors to be relaxed. Usually a CFA Bifactor model forces the general factor to be uncorrelated with the subfactors as well as subfactors with each other (Brown 2015). This could inflate item loadings on subfactors artificially especially in the context of our assumption that items might contribute to various sources of true score variance as above (Marsh et al. 2014; Marsh et al. 2009). A Bifactor ESEM, which allows cross-loadings between items, subfactors and a general factor, would thus be appropriate to allow proper allocation of construct relevant variance across items and factors (general and domain or subfactors) in this situation where one expects overlap but also unique contributions of items of PHS, optimism and pessimism of the LOT-R (Morin et al. 2016a). In addition to the fit indices of these models, their item factor loadings and correlations between latent variables in the measurement models, and direct effects in the structural models were examined.

The fit of the models was judged according to the cut-off points of $\mathrm{Hu}$ and Bentler (1999), supported by Geiser (2013), Byrne (2012), Wang and Wang (2019), among others. 
Thus, model fit is indicated by chi-square $\left(\chi^{2}\right)$, Root Mean Square Error of Approximation (RMSEA), Standardized Root Mean Square Residual (SRMR); Comparative Fit Index (CFI), Tucker-Lewis Index (TLI), and Akaike Information Criterion (AIC). According to them an adequate model is characterized by smaller and insignificant $\chi^{2}$, RMSEA and SRMR of less than 0.08; CFI of more than .95; TLI of more than .95; and smaller AIC (Byrne 2012; Geiser 2013; Hu and Bentler 1999; Wang and Wang 2019). In the direct effects structural models with which convergence and predictive validity were evaluated, standardised direct effects were judged on the basis of size, direction, and significance as shown by probability values of less than 0.05 and $95 \%$ confidence interval which excludes the zero point. Models 1 to 4 were also compared by means of the difference in $\chi^{2}\left(\Delta \chi^{2}\right)$ between successive models. The $\Delta \chi^{2}$ was adjusted by means of the Satorra-Bentler correction because the difference in subsequent $\chi^{2}$-values produced by the MLR estimator does not follow a $\chi^{2}$-distribution (Muthén and Muthén 2010).

Step 3 was dedicated to evaluating the predictive validity of the PHS with respect to the LOT-R and the Dispositional Hope Scale by means of a full SEM model consisting of a Bifactor ESEM measurement model and a structural model predicting well-being (Brown 2015). The estimator for all models were MLR and a bi-geomin rotation was done (Muthén and Muthén 2010). For our purposes, well-being consisted of four total scores, namely, depression/anxiety measured by the ultra-brief Patient Health Questionnaire for Depression and Anxiety (PHQ), life-satisfaction measured by the Satisfaction with Life Scale (SLS), harmony in life as measured by the Harmony in Life Scale (HLS), and subjective happiness measured by the Subjective Happiness Scale (SHS). To facilitate ease of interpretation, a latent variable called well-being constituted the four observable indicators.

Two Bifactor ESEM models were fitted, namely, one for a measurement model consisting of a general factor, and two sub- or domain factors representing PHS and LOT (Model 1), and one with a general factor and three subfactors representing PHS, LOT-R and Dispositional Hope (DHS) (Model 2). The structural models were the same for both, namely, well-being and its component factors. The double approach, namely, employing an ESEM and a Bifactor model in one fitting for the measurement model would simultaneously allow cross item and factor loadings and generate a general factor allowing true score variance to be allocated across items and factors without restrictions. One would thus, in theory, be able to see non-inflated or a more accurate allocation of variance to predict well-being. The suspicion that a general hope construct underlies most hope orientated instruments might be clarified with the fitting of Models 1 and 2, i.e., with and without Snyder's DHS. This also allowed us to determine the overlap between the three hope-related instruments, namely PHS, LOT-R and DHS.

Because of the exploratory nature of the Bi-ESEM model allowing cross-loadings without restriction, it does not make sense to specify subfactors for each instrument and their subscales, namely pessimism and optimism in the case of LOT-R and agency and pathway in the case of DHS. Too many domain factors could result in some non-significant domain factors as will be seen in Model 3 of Step 2 discussed below.

Reliability analyses in the study were guided by recommendations by McNeish (2017) and Raykov (2009), and thus did not apply Cronbach's alpha coefficient as an index of reliability. Instead, we computed the Omega hierarchical coefficients $\left(\omega_{\mathrm{h}}\right)(\mathrm{McNeish} 2017)$, which, unlike Cronbach's alpha, do not assume Tau equivalence, and rather take into account the variability of each item's contribution to the latent variable through factor loadings (Zinbarg et al. 2005). 


\section{Results}

\subsection{Step 1: Structural Validity of the PHS}

To test the model fit of the unidimensional 6 item PHS, a CFA model using MLR was estimated in two separate samples. The PHS performed well as a unidimensional measure of perceived hope in both samples. In the first sample $(N=244)$, model fit was indicated by $\chi^{2}(9)=50.147, p<.001 ; \mathrm{AIC}=3416 ; \mathrm{CFI}=.958 ; \mathrm{TLI}=.930 ; \mathrm{RMSEA}=.137(90 \% \mathrm{CI} .101$ $.175)$; SRMR $=.034$. The poor fitting RMSEA value can be ascribed to the small number and the homogenous nature of the sample. In the second sample $(N=409)$, model fit was indicated by $\chi^{2}(9)=27.270, p=.0013, \mathrm{AIC}=5672 ; \mathrm{CFI}=.981, \mathrm{TLI}=.969 ; \mathrm{RMSEA}=.070(90 \% \mathrm{CI}$ $.041 .102), \mathrm{SRMR}=.025$. In both cases, all indicator variables had high and significant factor loadings. For sample $1(n=244)$, they ranged from .777 ( $\mathrm{SE}=.032)$ for PHS4 to .953 ( $\mathrm{SE}=$ $.012)$ for PHS3 for PHS3. For sample $2(n=409)$ the loadings ranged from $.631(\mathrm{SE}=.032)$ for PHS2 to $.861(\mathrm{SE}=.024)$ for PHS5.

\subsection{Step 2: Assessment of the Discriminant Value of the PHS Compared to the LOT-R}

Step 2, including CFA and ESEM results as seen in Table 1, demonstrate empirical support for the distinction between PHS and LOT-R, more specifically that perceived hope, optimism, and pessimism are three separate latent variables. As expected, the one factor CFA model consisting of all the PHS and LOT-R items together (Model 1) proved to be ill fitting, $\chi^{2}(54)=517.217, p<.001, \mathrm{CFI}=.773$, TLI $=.722$. In contrast, the theoretically intended CFA model consisting of separate perceived hope, optimism, and pessimism first order latent variables (Model 2a) fitted the data well, $\chi^{2}(51)=104.440, p<.001$, CFI $=.974$, TLI $=.966$. Model $2 \mathrm{~b}$ in Table 1 was characterized by a two-factor second order model where perceived hope is distinguished from Life Orientation indicated by optimism and pessimism as latent factors, $\chi^{2}(51)=104.440, p<.001, C F I=.974, T L I=.966$. The results suggest that perceived hope can also be distinguished from Life Orientation as a unique second order measure composed by two first order factors.

The three factor CFA model was closely comparable with the marginally better Model 3, which represents the ESEM model testing the three factor model at first order level, $\chi^{2}(33)=$ 59.384, $p=.0032, \mathrm{CFI}=.987, \mathrm{TLI}=.974$. The Bifactor ESEM Model 4, with perceived hope, optimism, and pessimism as domain factors and one general factor fit the data very well with a non-significant $\chi^{2}(24)=32.868, p=.107, \mathrm{CFI}=.986$, and TLI $=.988$. The standardized loadings of the general and domain factors can be seen in Fig. 1 in the appendix. The models (1 to 4) all fit significantly better than the previous models. Table 1 provides the chi-square difference $\left(\Delta \chi^{2}\right)$ and degrees of freedom (df) for each comparison. Note that the second order model ( $2 \mathrm{~b}$ ) obtained exactly the same fit indices than Model 2a and may be discarded in subsequent discussions because we chose the more parsimonious Model 2a.

According to the factor loadings of Model 1, Model 2a, Model 3 and Model 4 as displayed in Table 2, all the items significantly loaded on their theoretically intended factors in both CFA and ESEM models, showing strong discriminant validity.

As seen in Table 3, perceived hope and optimism are highly correlated, showing $r=.786$ $(\mathrm{SE}=.036)$ in CFA Model 2a, and $\mathrm{r}=.757(\mathrm{SE}=.045)$ in ESEM Model 3. As expected, pessimism had moderate negative correlations with perceived hope, $r=-.283(\mathrm{SE}=.068)$ in CFA Model 2a, and $\mathrm{r}=-.309(\mathrm{SE}=.085)$ in ESEM Model 3. 


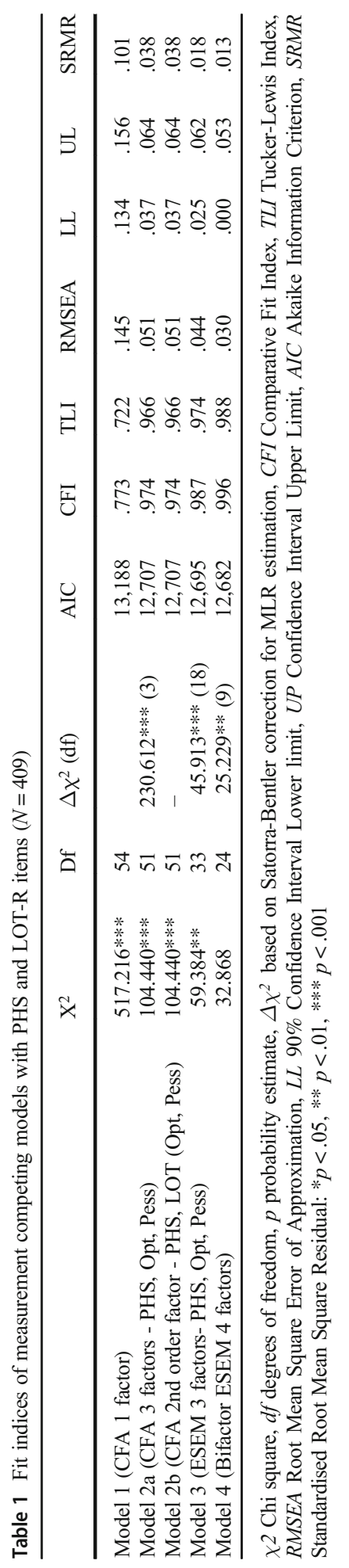




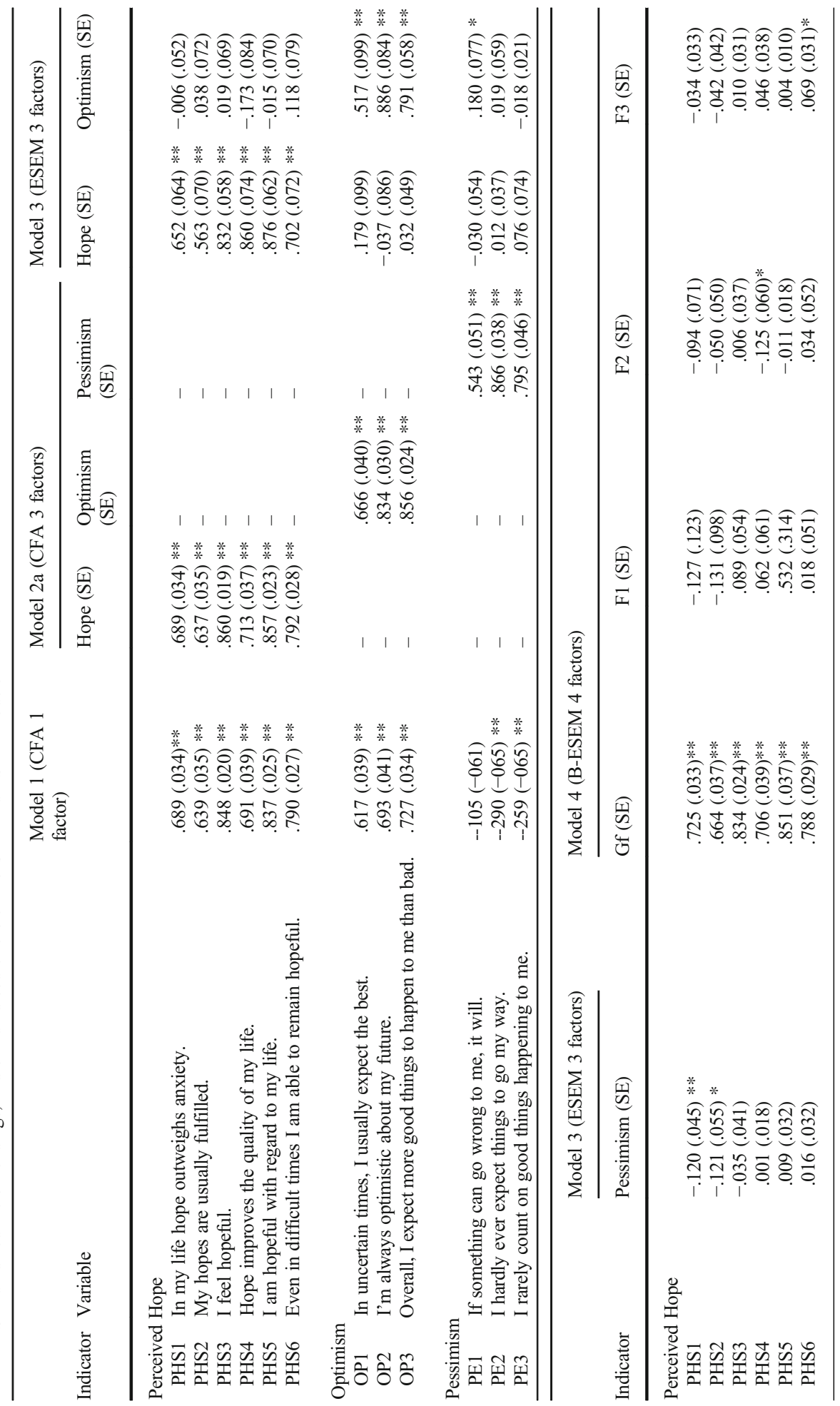




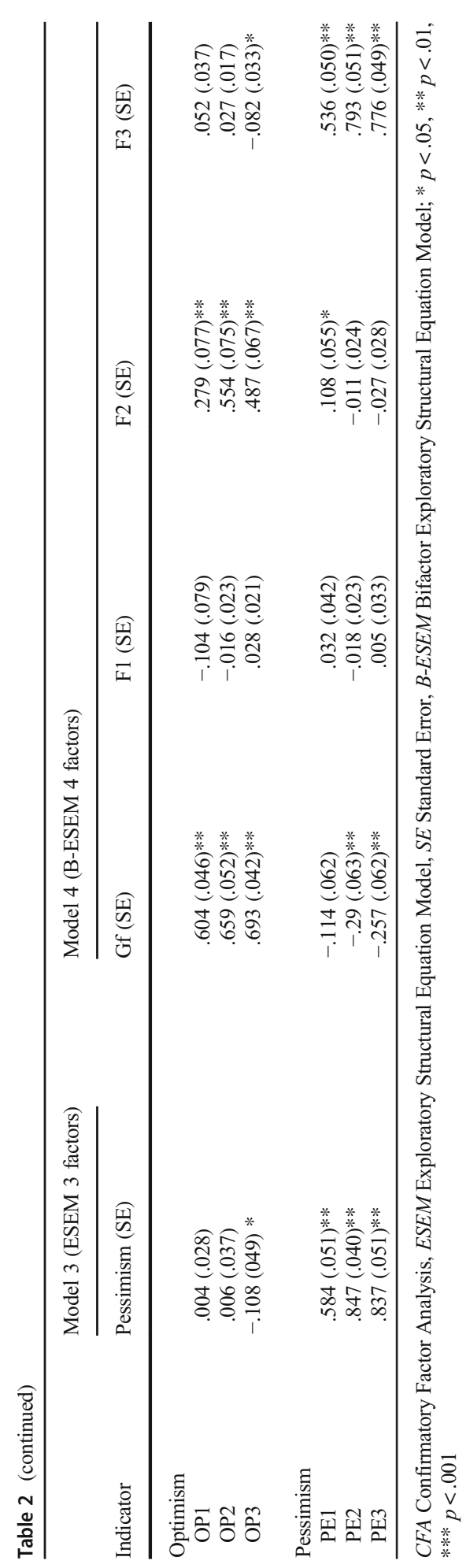


Table 3 Inter-variable correlations

\begin{tabular}{|c|c|c|c|}
\hline Variable & Optimism (SE) & Pessimism (SE) & General hope \\
\hline \multicolumn{4}{|c|}{ CFA Model (2a) with three factors } \\
\hline Perceived hope & $.79(.04)^{* * *}$ & $-.28(.07)^{* * *}$ & \\
\hline Optimism & - & $-.28(.08)^{* * *}$ & \\
\hline \multicolumn{4}{|c|}{ ESEM Model (3) with three factors } \\
\hline Perceived hope & $.76(.05)^{* * *}$ & $-.31(.09) * * *$ & \\
\hline Optimism & - & $-.28(.09)^{* *}$ & \\
\hline \multicolumn{4}{|c|}{ B-ESEM Model (4) with one general and three domain factors } \\
\hline Perceived hope & $-.05(.07)$ & $.12(.08)$ & $0(0)$ \\
\hline Optimism & - & $.01(.06)$ & $0(0)$ \\
\hline Pessimism & & - & $0(0)$ \\
\hline
\end{tabular}

CFA Confirmatory Factor Analysis, ESEM Exploratory Structural Equation Model, B-ESEM Bifactor Exploratory Structural Equation Model, $S E$ Standard Error; * $p<.05$, ** $p<.01$, *** $p<.001$

A surprising result, although not completely unexpected, is the almost non-existent crosscorrelations between the general factor and domain factors for the Bifactor ESEM Model 4 (Table 3). The general factor does not correlate with domain factors of optimism, pessimism or perceived hope, while the correlation between optimism and pessimism was $r=.013$ ( $\mathrm{SE}=$ $.064)$; between optimism and perceived hope $\mathrm{r}=-.046(\mathrm{SE}=.072)$, and between pessimism and perceived hope, $\mathrm{r}=.121(\mathrm{SE}=.075)$. These correlations were all non-significant. The substantial lack of significant correlations between the Bifactor ESEM's factors demonstrates the ability of an exploratory framework to overcome the restrictions upon which CFA is based (Marsh et al. 2009). The variance underlying the general factor inflated correlations between the factors in Models 2a and 3 along with the restriction of not allowing cross-correlations between items. The question is why the factor cross-correlations of the ESEM Model 3 are still of similar order than those of the CFA Model 2a? From the fit indices in Table 3 it is clear that Model 3 is a significant improvement on Model $2 \mathrm{a}(\Delta \chi 2=45.913 ; \mathrm{df}=18 ; p<.001)$ implying that although it is a better model, variance between the factors is still inflated. From Model 4 we should thus surmise that the general factor accounts for a substantial amount of true score variance across the two instruments' indicators. Table 2 shows the general factor accounted for most of the variance in the PHS indicators to such an extent that none of the standardised loadings of the PHS domain factor were significant (domain factor F1 in Table 2). The variance of the optimism indicators was accounted for by the domain optimism factor and the general factor and all loadings were significant (factors Gf and F2 in Table 2). This means that despite the overlap between optimism and PHS as shown by the general factor, optimism retained unique variance not overlapping with PHS. Pessimism indicators loaded negatively as expected on the general factor but only two were significant on the general factor (cf. indicators PE1, PE2 and PE3 in Table 2 and Gf factor), whilst the domain pessimism factor (domain factor F3 Table 2) accounted for unique variance on all three of its indicators. In sum, it seems as if the general factor accounts for most variance in the PHS indicators whilst the pessimism and optimism domain factors account for unique variance in their indicators thus supporting discriminant validity of the PHS and LOT-R. The moderate negative correlation between pessimism and perceived hope can be localized within the general hope/optimism factor which in the case of this Bifactor model seems to have the particular character of 
perceived hope. The general factor is essentially a perceived hope factor showing some overlap with optimism, but optimism retained enough significant variance to be a unique domain factor.

\subsection{Step 3: Predictive Power and Utility of the PHS Vis-á-Vis the LOT-R and the DHS}

This last step was dedicated to assessing the predictive power and utility of the PHS beyond dispositional optimism and dispositional hope. A bifactorial measurement model was fitted to the data and used to predict well-being in a structural model (see Appendix 2). The dependent variables used in the structural model are depression/anxiety (DAS), life-satisfaction (SLS), harmony in life (HLS) and subjective happiness (SHS). The measurement model consists of a general hope/optimism factor and domain factors, namely, PHS, agency and pathways representing DHS and optimism and pessimism representing LOT-R.

Table 4 presents the mean values, standard deviations, and bivariate correlations of the relevant variables. All variables, except pathways with pessimism, correlate significantly and in moderate terms with each other.

Table 5 provides the fit indices for the Bifactor ESEM measurement Model 1 with two subscales (or domain factors), consisting of items of the PHS and LOT-R as well as a general hope/optimism factor (see Appendix 2). The fit indices for Model 1 were $\chi 2(80)=224.780$, $p<.001, \mathrm{CFI}=.95$, and TLI $=.93$. All the PHS items loaded high $(.64-.86$ of which four items were above .70) on the general factor and non-significantly on the domain factors. Only three items loaded negatively on domain factors which means that the general factor absorbed almost all variance of PHS items indicating PHS to be a general hope construct. The LOT-R indicators load relatively strongly on the general factor (the optimism items loaded relatively high (namely .59-.70) but at the lower end of the PHS items). Only two of the pessimism indicators loaded significantly but negatively on the general factor. However, enough variance was available for a distinct domain factor with pessimism items. A distinct optimism construct was also formed. Both the domain factors predicted well-being significantly (pessimism -.21 and optimism .18) while the general factor predicted well-being substantially, namely, with a standardized estimate of .67.

Measurement Model 2 (see Appendix 2) in addition included the eight items from the DHS. The full structural Model 2 fit the data adequately with $\chi^{2}(194)=507.295, p<.001, \mathrm{CFI}=$ .931 , and TLI $=.901$ (Table 5). For this Bi-ESEM model, three domain factors and one general factor were specified. The PHS items loaded highly on the general factor (.63 to .82) with three items above .70. The three domain factors were constituted by the pathway items of the DHS, agency items, and mostly pessimism items of the LOT-R.

Again, the PHS items capture the general factor more substantially than the LOT-R and also the DHS. The general factor managed to predict well-being substantially with a loading of .73, whilst the agency and pessimism domain factors loaded .30 and -.14 respectively (both significant at $p<.05$ ) on well-being. An interesting finding is that the pathway domain factor could not predict well-being at all. By comparing the small increase in variance of the general factor predicting well-being of Model 1 (.68) without DHS to Model 2 (.73) with DHS, one could assume that the DHS contributed somewhat to the general factor's ability to predict wellbeing but also managed to predict well-being significantly on its own by means of agency (.30) but not pathways. The PHS accounts thus for most of the variance in well-being by means of the general factor along with the domain agency and pessimism factors. The finding is that PHS is mainly a generalised construct and LOT-R and DHS contribute to this generalised construct 


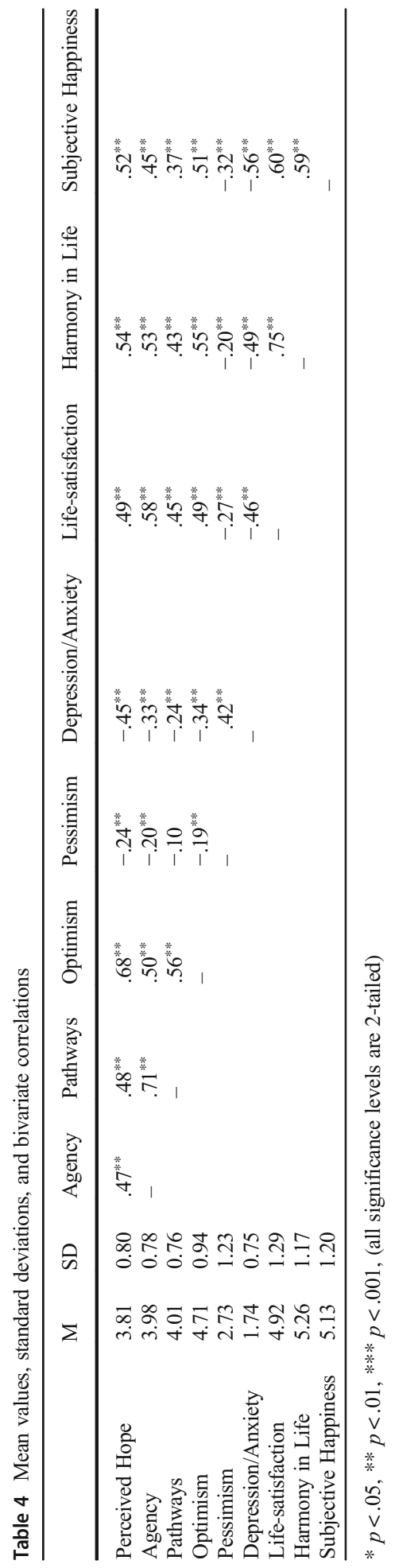


Table 5 Fit indices of the bifactor measurement models and the full predictive model with PHS, LOT-R, DHS items and well-being factors $(N=409)$

\begin{tabular}{llllllllll}
\hline Model & $\chi^{2}$ & Df & AIC & CFI & TLI & RMSEA & LL & UL & SRMR \\
\hline $\begin{array}{l}\text { Model 1 (Bifactor ESEM with PHS } \\
\text { and LOT-R) }\end{array}$ & $224.780^{* * *}$ & 80 & 16,680 & .950 & .926 & .067 & .056 & .077 & .043 \\
$\begin{array}{l}\text { Model 2 (Bifactor ESEM with PHS, } \\
\text { LOT- R and DHS) }\end{array}$ & $507.295^{* * *}$ & 194 & 23,872 & .931 & .901 & .063 & .056 & .070 & .038 \\
\hline
\end{tabular}

PHS Perceived Hope Scale, DHS Dispositional Hope Scale, LOT-R Life Orientation Test revised, $\chi 2$ Chi square, $d f$ degrees of freedom, $p$ probability estimate, CFI Comparative Fit Index, TLI Tucker-Lewis Index, RMSEA Root Mean Square Error of Approximation, $L L$ 90\% Confidence Interval Lower limit, UL Confidence Interval Upper Limit, AIC Akaike Information Criterion, BIC Bayesian Information Criterion, SRMR Standardised Root Mean Square Residual; * $p<.05, * * p<.01, * * * p<.001$

when related to well-being. LOT's Pessimism and DHS's agency form distinct domain factors predicting well-being significantly but not as substantially as the generalised construct.

\section{Discussion}

Against the background of the many and sometimes contradicting definitions of hope and optimism, the overall purpose of this contribution was to explore and evaluate the conceptual similarities and differences between hope and optimism, as measured by the Perceived Hope Scale (PHS) and the revised Life Orientation Test (LOT-R) and its subconstructs optimism and pessimism. Since several authors have pleaded for the necessity of a short and psychometrically sound scale to measure hope as perceived by the general population (Averill et al. 1990; Tennen et al. 2002; Tong et al. 2010), the first step consisted of assessing the factor structure and reliability of the English version of the PHS developed by Krafft et al. (2019). As conceptually expected, the unidimensional factor solution consisting of the six items of the PHS showed construct validity and reliability in two independent samples of the present study. These findings are similar to the results obtained with the German version of the scale (Krafft et al. 2019).

Whereas Krafft et al. (2019) demonstrated convergent and discriminant validity as well as predictive utility of the PHS in comparison to the Dispositional Hope Scale of Snyder et al. (1991), the objective of the current study was to assess these facets of validity of the PHS vis-á-vis the LOT-R. Based on theoretical considerations which maintain that hope and optimism are two different, albeit related, phenomena beyond mere cognitions (Averill et al. 1990; Bruininks and Malle 2005), step 2 evaluated the discriminant value of the PHS in relation to the LOT-R. The main finding here was the emergence of a conceptually aligned, empirically well-fitting model distinguishing perceived hope from optimism and pessimism. However, the interesting finding was that the conceptually distinct perceived hope formed a generalised factor and not a distinct domain factor. Thus, there is strong empirical evidence of discriminant validity of the PHS as a measure of perceived hope vis-á-vis the LOT-R as a measure of optimism and pessimism, as demonstrated by the tri-partite factor solution. This Bifactor-ESEM model, as shown through both the CFA and ESEM models, was superior over the unidimensional one, and the other configurations of bi-dimensional models. With the latent factors showing moderate theoretically expected associations, the independence of the PHS as a generalised construct 
from the optimism and pessimism sub-scales of the LOT-R was demonstrated. The discriminant relationship between PHS and LOT-R was supported by the BifactorESEM Model 4 (Table 2). The general factor of Model 4 (Table 2) accounted for most of the PHS indicators to such an extent that little unique variance was explained by the domain PHS factor. Thus, we found one general factor explaining PHS variance (and part of optimism variance) and two domain factors each accounting for optimism and pessimism enabling a clear distinction between the three factors.

These findings can be explained in the light of the conceptual distinction between hope and optimism discussed both in psychology and philosophy. Whereas hope entails the belief in the possibility (although not the likelihood) of a (highly) desired outcome, optimism reflects a higher confidence in terms of the subjective probability of realization assigned to a positive future state of affairs (Downie 1963; Bruininks and Malle 2005). Hope is distinct from optimism in that it is related to more uncertainty, lower probability, but higher personal importance and commitment as recently demonstrated by Gasper et al. (2020). This means, that the general factor of the Bifactor-ESEM (which predominantly represents the items of the PHS and to a lesser extent that of optimism) may correspond to the basic belief in that the realization of one's own wishes is possible (a necessary but not sufficient condition for optimism). Furthermore, the optimism domain factor might represent the additional positive expectation of a high(er) subjectively estimated likelihood.

Hence, in terms of probability assessment, optimism goes beyond perceived hope. However, perceived hope seems to capture general features of hope that might underlie related constructs (such as optimism and dispositional hope) but at the same time bring into evidence aspects of hope which are lacking in those constructs. The empirical evidence for a clear distinction between the PHS and the LOT-R items, on the one hand, and the fact that the general hope/optimism factor is represented mainly by the PHS items and to a lesser extent by the LOT-R (and the DHS), could be interpreted as an indication for the distinct value of the PHS that goes beyond optimism, for instance regarding the importance of and the commitment or attachment to a positive future outcome. Perceived hope can thus represent a fundamental positive attitude towards the future that people sustain sometimes regardless of their low expectancies (and despite the occasional difficulty to take on agency). This could be an interesting point of departure for new research questions in future empirical studies.

Finally, the third step evaluated the predictive power and utility of the PHS vis-á-vis the LOT-R and its subscales for optimism and pessimism, and the DHS and its subscales of agency and pathways in relation to anxiety/depression, life-satisfaction, happiness and harmony in life, represented by a latent factor we called well-being. A general factor accounted for almost all the variance of the PHS indicators and was also responsible for predicting a substantial portion of well-being (.72). Along with the domain factors of agency and pessimism, the general factor could predict well-being significantly. Pathways and optimism, incidentally, could not on their own predict well-being. PHS, as a general factor, added to the prediction of these outcomes related to health and well-being besides dispositional optimism and pessimism as well as dispositional agency and pathways. These results support the idea that hope as perceived by people is not identical with agency, pathways, optimism and the inverse of pessimism, involving further elements not addressed by these variables. Both steps 2 and 3 show that the generalised construct which is captured by the PHS is a crucial element of hope able to predict well-being beyond the 
unique parts of LOT-R and DHS. The PHS, again, seems to capture a generalised construct and this particular generalised element is present in the LOT-R and the DHS but at the same time contains aspects or qualities distinct from them.

\section{Limitations}

Despite several promising findings, we are aware of some limitations of our study. The first limitation resides in the cross-sectional nature of the Hope-Barometer that makes it impossible to study the causal impact of hope and optimism on well-being. This can only be assessed using a longitudinal research strategy. A further limitation is that, although we based our analyses on a heterogeneous group of people, the sample is not strictly representative of the demographics of the South African population. The participants were rather people with Internet literacy and access. However, the advantages of web-based research reside in the larger size and the mixed composition of the sample. Finally, the findings and conclusions gained from our analyses are restricted to South Africa, making it necessary to explore and evaluate the generalizability of the results to other nations and cultures.

\section{Conclusions}

The PHS proved to be a reliable and psychometrically robust scale to measure hope as perceived by people, which can be clearly distinguished from dispositional optimism and pessimism and which adds to the prediction of health and well-being besides the contribution of dispositional hope (especially in terms of agency), and future expectancies in terms of optimism and pessimism. Our results indicate there is a general underlying hope factor involved in predicting a large part of well-being and health constructs. Our study thus expands the current cognitive theoretical frameworks of hope by adding evidence of how hope is perceived by ordinary people and that this perception can contribute to health and well-being, beyond positive expectancies. However, in everyday life hope and optimism seem to be less clearly distinguished than often conceptualized by philosophers and psychology researchers. Our findings support the necessity of further research accounting for different targets and domains of hope, exploring the nature and the character of the common factor underlying related hope/optimism constructs. The South African sample with its specific cultural values and norms opens profitable and interesting future investigations of hope as it manifests in different parts of the world.

Funding Open Access funding provided by Universität St. Gallen. This research did not receive any specific grant from funding agencies in the public, commercial, or not-for-profit sectors.

Materials The data that support the findings of this study is available from the corresponding author upon request.

\section{Compliance with Ethical Standards}

Conflict of Interest The authors declare that they have no conflict of interest. 


\section{Appendix 1}

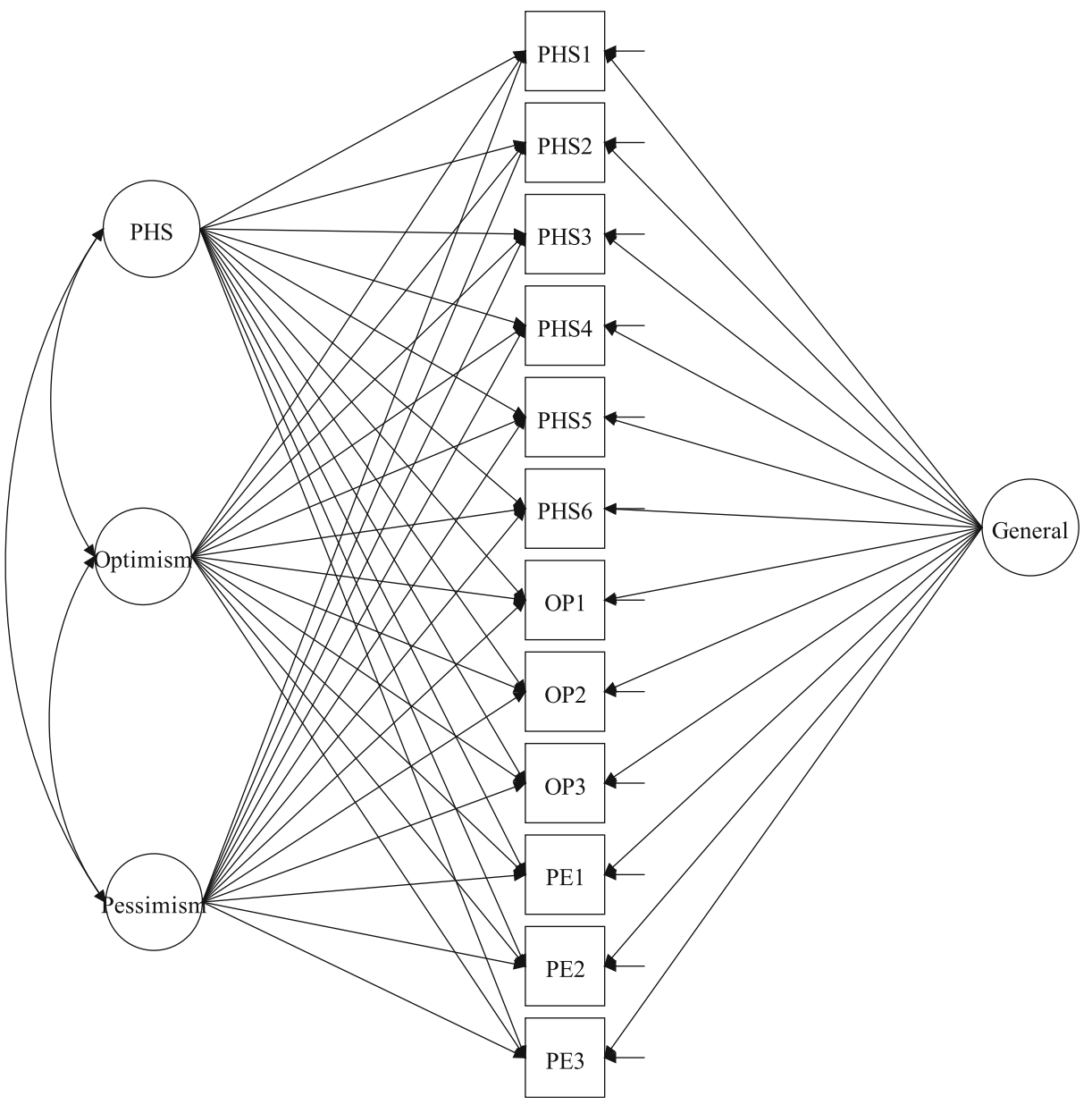




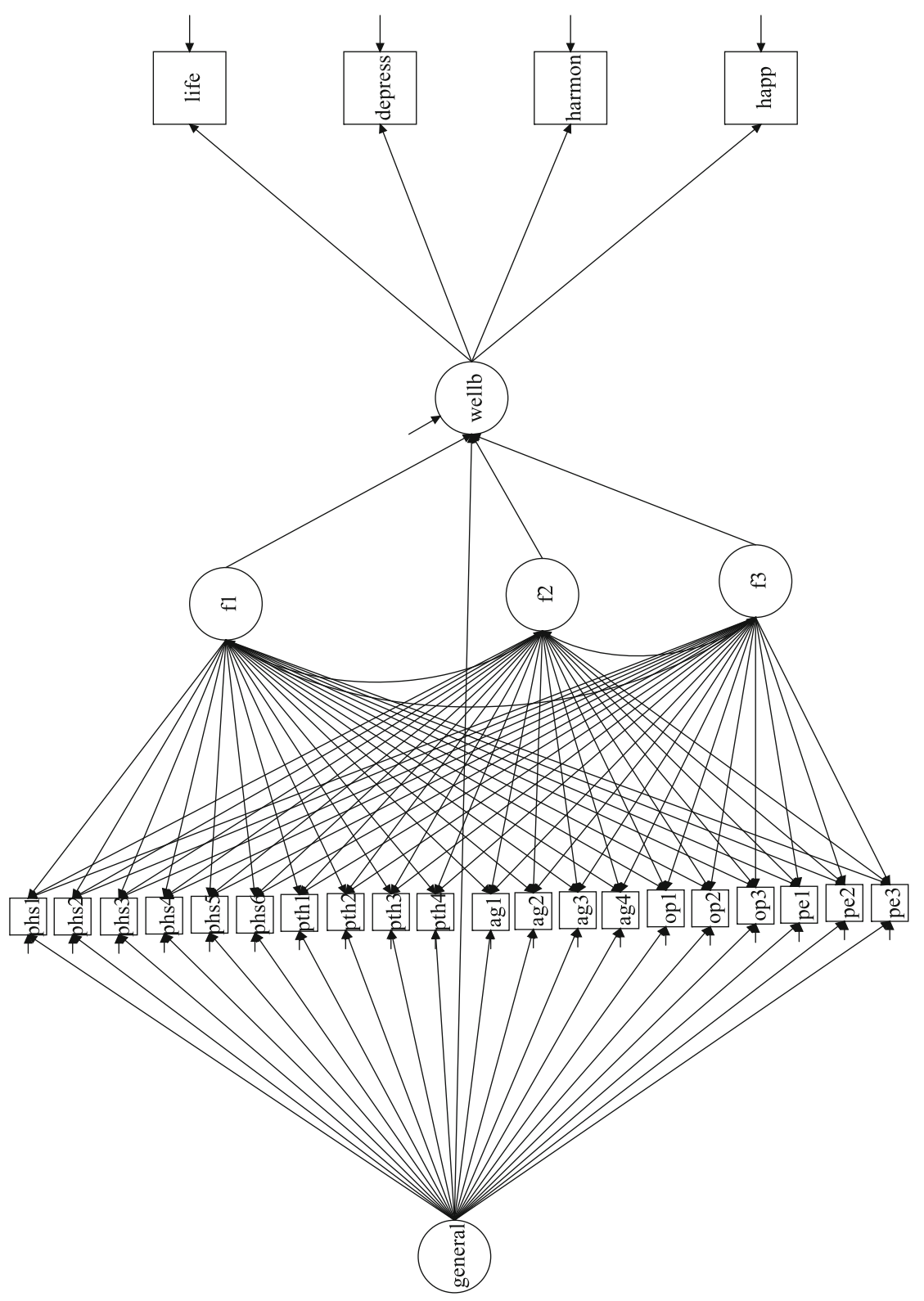

爰妾 
Open Access This article is licensed under a Creative Commons Attribution 4.0 International License, which permits use, sharing, adaptation, distribution and reproduction in any medium or format, as long as you give appropriate credit to the original author(s) and the source, provide a link to the Creative Commons licence, and indicate if changes were made. The images or other third party material in this article are included in the article's Creative Commons licence, unless indicated otherwise in a credit line to the material. If material is not included in the article's Creative Commons licence and your intended use is not permitted by statutory regulation or exceeds the permitted use, you will need to obtain permission directly from the copyright holder. To view a copy of this licence, visit http://creativecommons.org/licenses/by/4.0/.

\section{References}

Alarcon, G. M., Bowling, N. A., \& Khazon, S. (2013). Great expectations: A meta-analytic examination of optimism and hope. Personality and Individual Differences, 54(7), 821-827.

Andersson, G. (1996). The benefits of optimism: A meta-analytic review of the life orientation test. Personality and Individual Differences, 21(5), 719-725.

Asparouhov, T., \& Muthén, B. (2009). Exploratory structural equation modelling. Structural Equation Modelling: A Multidisciplinary Journal, 16(3), 397-438.

Aspinwall, L. G., \& Leaf, S. L. (2002). In search of the unique aspects of hope: Pinning our hopes on positive emotions, future-oriented thinking, hard times, and other people. Psychological Inquiry, 13(4), 276-288.

Averill, J. R., \& Sundararajan, L. (2005). Hope as rhetoric: Cultural narratives of wishing and coping. In J. Eliott (Ed.), Interdisciplinary perspectives on hope (pp. 133-165). New York: Nova Science.

Averill, J. R., Catlin, G., \& Chon, K. K. (1990). Rules of hope: Recent research in psychology. New York: Springer.

Bailey, T. C., Eng, W., Frisch, M. B., \& Snyder, C. R. (2007). Hope and optimism as related to life satisfaction. The Journal of Positive Psychology, 2(3), 168-175.

Benyamini, Y., \& Roziner, I. (2008). The predictive validity of optimism and affectivity in a longitudinal study of older adults. Personality and Individual Differences, 44(4), 853-864.

Benzein, E., Norberg, A., \& Saveman, B. I. (2001). The meaning of the lived experience of hope in patients with cancer in palliative home care. Palliative Medicine, 15(2), 117-126.

Brown, T. A. (2015). Confirmatory factor analysis for applied research (2nd ed.). New York: Guilford.

Bruininks, P., \& Malle, B. F. (2005). Distinguishing hope from optimism and related affective states. Motivation and Emotion, 29(4), 324-352.

Byrne, B. M. (2012). Structural equation modeling with Mplus: Basic concepts, applications, and programming. New York: Routledge.

Carver, C. S., \& Scheier, M. F. (1981). Attention and self-regulation: A control-theory approach to human behavior. New York: Springer-Verlag.

Carver, C. S., \& Scheier, M. F. (2003). Optimism. In S. J. Lopez \& C. R. Snyder (Eds.), Positive psychological assessment: A handbook of models and measures (pp. 231-243). Washington, DC: American Psychological Association.

Carver, C. S., \& Scheier, M. F. (2014). Dispositional optimism. Trends in Cognitive Sciences, 18(6), $293-299$.

Carver, C. S., Scheier, M. F., \& Segerstrom, S. C. (2010). Optimism. Clinical Psychology Review, 30(7), 879-889.

Chang, E. C., \& Sanna, L. J. (2001). Optimism, pessimism, and positive and negative affectivity in middle-aged adults: A test of a cognitive-affective model of psychological adjustment. Psychology and Aging, 16(3), 524-531.

Chang, E. C., Maydeu-Olivares, A., \& D'Zurilla, T. J. (1997). Optimism and pessimism as partially independent constructs: Relationship to positive and negative affectivity and psychological well-being. Personality and Individual Differences, 23(3), 433-440.

Cheavens, J. S., Michael, S. T., \& Snyder, C. R. (2005). The correlates of Hope: Psychological and physiological benefits. In J. Eliott (Ed.), Interdisciplinary perspectives on hope (pp. 119-132). New York: Nova Science.

Clayton, J. M., Hancock, K., Parker, S., Butow, P. N., Walder, S., Carrick, S., Currow, D., Ghersi, D., Glare, P., Hagerty, R., Olver, I. N., \& Tattersall, M. H. N. (2008). Sustaining hope when communicating with terminally ill patients and their families: A systematic review. Psycho-Oncology, 17(7), 641-659.

David, D., Montgomery, G. H., Stan, R., DiLorenzo, T., \& Erblich, J. (2004). Discrimination between hopes and expectancies for nonvolitional outcomes: Psychological phenomenon or artifact? Personality and Individual Differences, 36(8), 1945-1952.

Diener, E. D., Emmons, R. A., Larsen, R. J., \& Griffin, S. (1985). The satisfaction with life scale. Journal of Personality Assessment, 49(1), 71-75.

, R. S. (1963). Hope. Philosophy and Phenomenological Research, 24(2), 248-251. 
Dufault, K., \& Martocchio, B. C. (1985). Symposium on compassionate care and the dying experience. Hope: Its spheres and dimensions. The Nursing Clinics of North America, 20(2), 379-391.

Eliott, J. A. (2005). What have we done with hope? A brief history. In J. Eliott (Ed.), Interdisciplinary perspectives on hope (pp. 3-45). New York: Nova Science.

Eliott, J., \& Olver, I. N. (2002). The discursive properties of "hope": A qualitative analysis of cancer patients' speech. Qualitative Health Research, 12(2), 173-193.

Erikson, E. (1963). Childhood and Society (2nd ed.). New York: W.W. Norton \& Co.

Farran, C. J., Herth, K. A., \& Popovich, J. M. (1995). Hope and hopelessness: Critical clinical constructs. New York: Sage.

Fredrickson, B. L. (2002). How does religion benefit health and well-being? Are positive emotions active ingredients? Psychological Inquiry, 13(3), 209-213.

Fredrickson, B. L. (2013). Positive emotions broaden and build. Advances in Experimental Social Psychology, 47(1), 1-53.

Gasper, K., Spencer, L. A., \& Middlewood, B. L. (2020). Differentiating hope from optimism by examining selfreported appraisals and linguistic content. The Journal of Positive Psychology, 15(2), 220-237.

Geiser, C. (2013). Data analysis with Mplus. New York: Guilford Press.

Glaesmer, H., Rief, W., Martin, A., Mewes, R., Brähler, E., Zenger, M., \& Hinz, A. (2012). Psychometric properties and population-based norms of the life orientation test revised (LOT-R). British Journal of Health Psychology, 17(2), 432-445.

Herth, K. (1991). Development and refinement of an instrument to measure hope. Scholarly Inquiry for Nursing Practice, 5(1), 39-51.

Herth, K. (2005). State of the science of Hope in nursing practice: Hope, the nurse, and the patient. In J. Eliott (Ed.), Interdisciplinary perspectives on hope (pp. 169-213). New York: Nova Science.

Herzberg, P. Y., Glaesmer, H., \& Hoyer, J. (2006). Separating optimism and pessimism: A robust psychometric analysis of the revised life orientation test (LOT-R). Psychological Assessment, 18(4), 433-438.

Hu, L., \& Bentler, P. M. (1999). Cutoff criteria for fit indexes in covariance structure analysis: Conventional criteria versus new alternatives. Structural Equation Modeling: A Multidisciplinary Journal, 6(1), 1-55.

Kamihara, J., Nyborn, J. A., Olcese, M. E., Nickerson, T., \& Mack, J. W. (2015). Parental hope for children with advanced cancer. Pediatrics, $135(5), 868-874$.

Kjell, O., Daukantaité, D., Hefferon, K., \& Sikström, S. (2016). Harmony in life scale complements the satisfaction with life scale: Expanding the conceptualization of the cognitive component of subjective well-being. Social Indicators Research, 126, 893-919.

Krafft, A.M., Walker, A.M. (2018a) Exploring the concept and experience of Hope - Theoretical and methodological foundations. In Krafft A.M., Perrig-Chiello, P. \& Walker A.M. (Eds.) Hope for a good life: Results of the Hope-Barometer International Research Program (pp. 3-19). Springer Int.: Cham.

Krafft, A. M., \& Walker, A. M. (2018b). Exploring the concept and experience of Hope-Empirical findings and the virtuous circle of Hope. In A. M. Krafft, P. Perrig-Chiello, \& A. M. Walker (Eds.), Hope for a good life: Results of the Hope-Barometer International Research Program (pp. 21-60). Cham: Springer Int..

Krafft, A. M., Martin-Krumm, C., \& Fenouillet, F. (2019). Adaptation, further elaboration, and validation of a scale to measure hope as perceived by people: Discriminant value and predictive utility vis-à-vis dispositional Hope. Assessment, 26(8), 1594-1609.

Kroenke, K., Spitzer, R. L., Williams, J. B., \& Löwe, B. (2009). An ultra-brief screening scale for anxiety and depression: The PHQ-4. Psychosomatics, 50(6), 613-621.

Kubzansky, L. D., Kubzansky, P. E., \& Maselko, J. (2004). Optimism and pessimism in the context of health: Bipolar opposites or separate constructs? Personality and Social Psychology Bulletin, 30(8), 943-956.

Leung, K. K., Silvius, J. L., Pimlott, N., Dalziel, W., \& Drummond, N. (2009). Why health expectations and hopes are different: The development of a conceptual model. Health Expectations, 12(4), 347-360.

Lopez, S. J., Snyder, C. R., \& Pedrotti, J. T. (2003). Hope: Many definitions, many measures. In S. J. Lopez \& C. R. Snyder (Eds.), Positive psychological assessment: A handbook of models and measures (pp. 91-106). Washington, DC: American Psychological Association.

Lyubomirsky, S., \& Lepper, H. S. (1999). A measure of subjective happiness: Preliminary reliability and construct validation. Social Indicators Research, 46(2), 137-155.

Magaletta, P. R., \& Oliver, J. M. (1999). The hope construct, will, and ways: Their relations with self-efficacy, optimism, and general well-being. Journal of Clinical Psychology, 55(5), 539-551.

Marsh, H. W., Muthén, B., Asparouhov, T., Lüdtke, O., Robitzsch, A., Morin, A. J. S., \& Trautwein, U. (2009). Exploratory structural equation modeling, integrating CFA and EFA: Application to students' evaluations of university teaching. Structural Equation Modeling: A Multidisciplinary Journal, 16(3), 439-476. https://doi. org/10.1080/10705510903008220. 
Marsh, H. W., Morin, A. J. S., Parker, P. D., \& Kaur, G. (2014). Exploratory structural equation modeling: An integration of the best features of exploratory and confirmatory factor analysis. Annual Review of Clinical Psychology, 10, 85-110. https://doi.org/10.1146/annurev-clinpsy-032813-153700.

Marshall, G. N., Wortman, C. B., Kusulas, J. W., Hervig, L. K., \& Vickers Jr., R. R. (1992). Distinguishing optimism from pessimism: Relations to fundamental dimensions of mood and personality. Journal of Personality and Social Psychology, 62(6), 1067.

McLarnon, M. J. W., \& Tarraf, R. C. (2017). The dark triad: Specific or general sources of variance? A bifactor exploratory structural equation odelling approach. Personality and Individual Differences, 112, 67-73. https://doi.org/10.1016/j.paid.2017.02.049.

McNeish, D. (2017). Thanks coefficient alpha, We'll take it from here. Psychological Methods, Advance online publication, 1-22. https://doi.org/10.1037/met0000144.

Miller, G. (2012). Hope is a virtue. Journal of Child Neurology, 27(12), 1616-1617.

Montgomery, G. H., David, D., DiLorenzo, T., \& Erblich, J. (2003). Is hoping the same as expecting? Discrimination between hopes and response expectancies for nonvolitional outcomes. Personality and Individual Differences, 35(2), 399-409.

Morin, A. J. S., Arens, A. K., \& Marsh, H. W. (2016a). A bifactor exploratory structural equation modeling framework for the identification of distinct sources of construct-relevant psychometric multidimensionality. Structural Equation Modeling: A Multidisciplinary Journal, 23(1), 116-139. https://doi.org/10.1080/ 10705511.2014.961800.

Morin, A. J. S., Arens, A. K., Tran, A., \& Caci, H. (2016b). Exploring sources of construct-relevant multidimensionality in psychiatric measurement: A tutorial and illustration using the composite scale of morningness. International Journal of Methods in Psychiatric Research, 25(4), 277-288. https://doi.org/ $10.1002 / \mathrm{mpr} .1485$.

Muthén, L. K., \& Muthén, B. O. (1998-2017). Mplus statistical analysis with latent variables: Users' guide (8th ed.). Los Angeles: Muthén \& Muthén.

Muthén, B. O., \& Muthén, L. K. (2010). Chi-square difference testing using the Satorra-Bentler scaled chi square. Retrieved from https://www.statmodel.com/chidiff.shtml. Accessed 22 Aug 2020.

Peterson, C., \& Seligman, M. E. (2004). Character strengths and virtues: A handbook and classification. Oxford: Oxford University Press.

Pruyser, P. W. (1986). Maintaining hope in adversity. Pastoral Psychology, 35(2), 120-131.

Rasmussen, H. N., Scheier, M. F., \& Greenhouse, J. B. (2009). Optimism and physical health: A meta-analytic review. Annals of Behavioral Medicine, 37(3), 239-256.

Raykov, T. (2009). Evaluation of scale reliability for unidimensional measures using latent variable modeling. Measurement and Evaluation in Counseling and Development, 42(3), 223-232.

Raykov, T., \& Marcoulides, G. A. (2012). An introduction to applied multivariate analysis. New York, London: Routledge.

Renz, M., Koeberle, D., Cerny, T., \& Strasser, F. (2009). Between utter despair and essential hope. Journal of Clinical Oncology, 27(1), 146-149.

Ribeiro, J. L. P., Pedro, L., \& Marques, S. (2012). Dispositional optimism is unidimensional or bidimensional? The Portuguese revised life orientation test. The Spanish Journal of Psychology, 15(3), 1259-1271.

Robinson-Whelen, S., Kim, C., MacCallum, R. C., \& Kiecolt-Glaser, J. K. (1997). Distinguishing optimism from pessimism in older adults: Is it more important to be optimistic or not to be pessimistic? Journal of Personality and Social Psychology, 73(6), 1345.

Scheier, M. F., \& Carver, C. S. (1985). Optimism, coping, and health: Assessment and implications of generalized outcome expectancies. Health Psychology, 4(3), 219-247.

Scheier, M. F., Carver, C. S., \& Bridges, M. W. (1994). Distinguishing optimism from neuroticism (and trait anxiety, self-mastery, and self-esteem): A reevaluation of the life orientation test. Journal of Personality and Social Psychology, 67(6), 1063-1078.

Scheier, M. F., Carver, C. S., \& Bridges, M. W. (2001). Optimism, pessimism, and psychological well-being. In E. C. Chang (Ed.), Optimism and pessimism: Implications for theory, research, and practice (pp. 189-216). Washington, DC: American Psychological Association.

Scioli, A., \& Biller, H. (2009). Hope in the age of anxiety. Oxford: Oxford University Press.

Scioli, A., Chamberlin, C. M., Samor, C. M., Lapointe, A. B., Campbell, T. L., Macleod, A. R., \& McLenon, J. (1997). A prospective study of hope, optimism, and health. Psychological Reports, 81(3), 723-733.

Scioli, A., Ricci, M., Nyugen, T., \& Scioli, E. R. (2011). Hope: Its nature and measurement. Psychology of Religion and Spirituality, 3(2), 78-97.

Segerstrom, S. C., Evans, D. R., \& Eisenlohr-Moul, T. A. (2011). Optimism and pessimism dimensions in the life orientation test-revised: Method and meaning. Journal of Research in Personality, 45(1), 126-129. 
Shirado, A., Morita, T., Akazawa, T., Miyashita, M., Sato, K., Tsuneto, S., \& Shima, Y. (2013). Both maintaining hope and preparing for death: Effects of physicians' and nurses' behaviors from bereaved family members' perspectives. Journal of Pain and Symptom Management, 45(5), 848-858.

Smith, T. W., Pope, M. K., Rhodewalt, F., \& Poulton, J. L. (1989). Optimism, neuroticism, coping, and symptom reports: An alternative interpretation of the life orientation test. Journal of Personality and Social Psychology, 56(4), 640-648.

Snyder, C. R. (1994). The psychology of hope: You can get there from here. New York: Simon and Schuster.

Snyder, C. R. (2002). Hope theory: Rainbows in the mind. Psychological Inquiry, 13(4), 249-275.

Snyder, C. R., Harris, C., Anderson, J. R., Holleran, S. A., Irving, L. M., Sigmon, S. T., \& Harney, P. (1991). The will and the ways: Development and validation of an individual-differences measure of hope. Journal of Personality and Social Psychology, 60(4), 570-585.

Snyder, C. R., Sympson, S. C., Michael, S. T., \& Cheavens, J. (2001). Optimism and hope constructs: Variants on a positive expectancy theme. In E. C. Chang (Ed.), Optimism and pessimism: Implications for theory, research, and practice (pp. 101-125). Washington, DC: American Psychological Association.

Stenling, A., Ivarsson, A., Hassmén, P., \& Lindwall, M. (2015). Using bifactor exploratory structural equation modeling to examine global and specific factors in measures of sports coaches' interpersonal styles. Frontiers in Psychology, 6, Article 01303. https://doi.org/10.3389/fpsyg.2015.01303.

Tennen, H., Affleck, G., \& Tennen, R. (2002). Clipped feathers: The theory and measurement of hope. Psychological Inquiry, 13(4), 311-317.

Tong, E. M., Fredrickson, B. L., Chang, W., \& Lim, Z. X. (2010). Re-examining hope: The roles of agency thinking and pathways thinking. Cognition and Emotion, 24(7), 1207-1215.

Vaillant, G. E. (2008). Spiritual evolution: How we are wired for faith, hope, and love. NY: Broadway Books. van der Geest, I. M., van den Heuvel-Eibrink, M. M., Falkenburg, N., Michiels, E. M., van Vliet, L., Pieters, R., \& Darlington, A. S. E. (2015). Parents' faith and hope during the pediatric palliative phase and the association with long-term parental adjustment. Journal of Palliative Medicine, 18(5), 402-407.

Wang, J., \& Wang, X. (2019). Structural equation modeling: Applications using Mplus (2nd ed.). West Sussex: Wiley.

West, S. G., Finch, J. F., \& Curran, P. J. (1995). Structural equation models with non-normal variables: Problems and remedies. In R. H. Hoyle (Ed.), Structural equation modeling (pp. 56-75). London: Sage.

WHOQOL-SRPB Group. (2002). WHOQOL-SRPB users manual: Scoring and coding for the WHOQOL SRPB field test instrument. Geneva: World Health Organization.

Zinbarg, R. E., Revelle, W., Yovel, I., \& Li, W. (2005). Cronbach's $\alpha$, Revelle's $\beta$, and Mcdonald's $\omega_{\mathrm{H}}$ : Their relations with each other and two alternative conceptualizations of reliability. Psychometrika, 70(1), 123-133.

Publisher's Note Springer Nature remains neutral with regard to jurisdictional claims in published maps and institutional affiliations.

\section{Affiliations}

\section{Andreas M. Krafft ${ }^{1} \cdot$ Tharina Guse $^{2} \cdot$ David Maree $^{3}$}

Tharina Guse

tharina.guse@up.ac.za

David Maree

david.maree@up.ac.za

1 Institute of Systemic Management and Public Governance, University of St. Gallen, Dufourstr. 40a, 9000 St. Gallen, Switzerland

2 Department of Psychology, University of Pretoria, Private Bag X20, Hatfield 0028, South Africa

3 Department of Psychology, University of Pretoria, Lynnwood Road, Hatfield 0083, South Africa 